$\therefore \begin{array}{ll}\text { Rock star } \\ \therefore \quad \therefore \quad \begin{array}{l}\text { Astronomers net } \\ \text { largest Kuiper-belt } \\ \text { object }\end{array} \\ \text { p546 }\end{array} \quad \begin{aligned} & \text { Trial run } \\ & \text { Switzerland lays } \\ & \text { down the law on } \\ & \text { transgenic crops } \\ & \text { p547 }\end{aligned}$

\title{
Regulators split on gene therapy as patient shows signs of cancer
}

\section{Erika Check, Washington}

The revelation last week that experimental gene therapy may have given a child a cancer-like illness has provoked diverse regulatory responses around the world.

The child was involved in a trial to treat severe combined immunodeficiency disease (SCID), a condition that disrupts the early development of the immune system.

France and the United States immediately suspended all SCID gene-therapy trials, whereas Britain elected to continue enrolling and treating patients in its two studies. Germany, by contrast, had already suspended a wider range of 13 similar gene-therapy trials in June, following reports that the technique may cause cancer in mice.

The SCID patient is a three-year-old French boy taking part in a clinical trial run by gene-therapy pioneer Alain Fischer of the Necker Hospital for Sick Children in Paris. SCID is fatal if not treated by a bone-marrow transplant. But many children lack a perfectly matched donor, and of these about $30-40 \%$

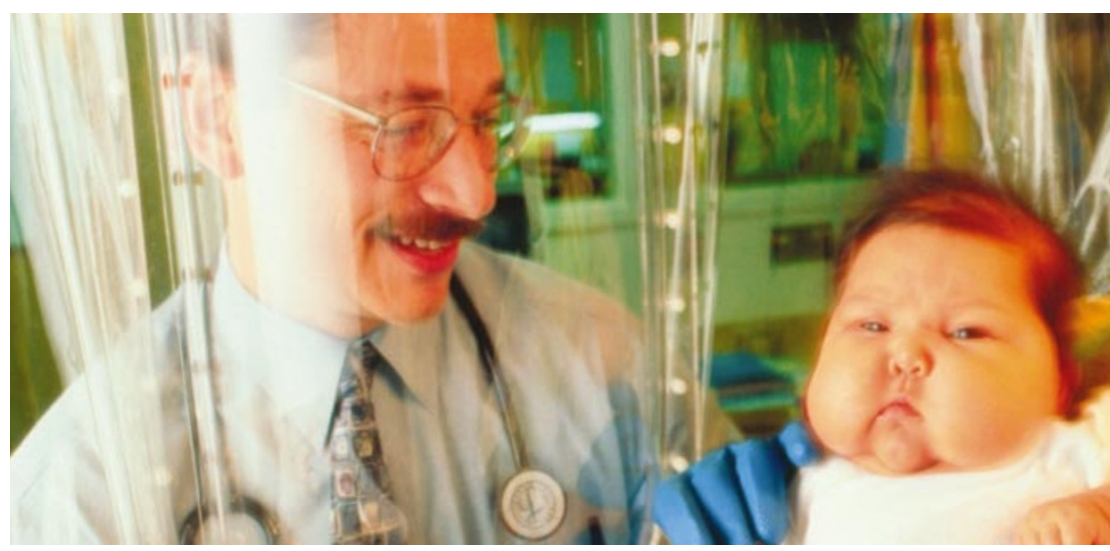

Don Kohn has successfully used gene therapy to treat children with severe combined immunodeficiency.

who suffer from a particular form of SCID die.

Fischer's technique hinges on a gene for a receptor that triggers the normal development of cells in the immune system. He uses a retrovirus to ferry the corrective gene to bonemarrow cells, and has so far cured 10 children.

\section{China ponders joining fusion project}

\section{Geoff Brumfiel, Washington}

Chinese officials are set to meet with negotiators from the European Union, Japan, Russia and Canada in Tokyo to discuss possible involvement in ITER - formerly the International Thermonuclear Experimental Reactor - which many believe is the next step in developing fusion power.

Officials at the Chinese ministry for science and technology have written to senior negotiators in each of the four ITER member states to express a "strong interest" in Chinese participation, says Paul Vandenplas, emeritus professor of the Royal Military Academy in Brussels, Belgium, and part of the European Union's negotiating team.

Vandenplas says that China would like to become a full partner in the US\$4-billion collaboration. This would require China to contribute about $\$ 100$ million per year in cash or equipment.
The Tokyo meeting will take place just after an official site-negotiation meeting in Rokkasho, Japan, at the end of this month. Vandenplas says that ITER's member states will provide China with information about the project and will informally discuss China's participation in negotiations.

China has a small but growing fusion programme, and officials - including the country's president, Jiang Zemin — have recently shown increasing interest in the field, says David Baldwin, head of fusion research at General Atomics in San Diego, California. "People who have visited Chinese laboratories are very impressed with the depth of knowledge," he adds.

US government officials have declared that the United States plans to rejoin ITER, which it left in 1999 (see Nature 417, 676; 2002) but no official announcement has been made.
But routine checks revealed worrying signs that the boy, one of those 10, had developed a leukaemia-like illness. The incident could have wide implications for the troubled field of gene therapy, as Fischer's SCID treatment had been the field's greatest success to date.

The widely diverging reactions to the news highlight the difficulty of balancing the immediate risks posed by some clinical trials against their long-term potential benefits. In the United States, the Institute of Medicine has just proposed reforms in a bid to get the balance right (see page 546). And the US Food and Drug Administration (FDA) has called a meeting this week to discuss how to proceed with gene therapies for SCID and other diseases.

Clinical researchers attribute the varying responses to the French boy's condition to a multitude of cultural, political and scientific factors. French authorities are sensitive to the fact that the adverse event occurred there, and US regulators are acutely aware of questions that were raised after the death of 18-year-old Jesse Gelsinger in a gene-therapy trial three years ago. Germany, meanwhile, maintains a generally cautious approach to research on human subjects, whereas Britain tends to take a more permissive approach, in the hope that such research will yield major benefits.

"Different countries are taking slightly different positions - the British are being 
very open-minded and the Germans want to block everything," says Fischer. At this point, he adds, it seems reasonable to halt gene-therapy trials that use retroviruses to target bone-marrow cells.

Retroviruses insert themselves randomly into DNA, but scientists have long worried that this activity has the potential to promote uncontrolled cell growth.

In the French child's case, Fischer says the retroviral vector has inserted itself into a stretch of DNA that regulates the gene LMO2. This gene can cause leukaemia and the boy's defective immune cells seem to be expressing LMO2. This raises the possibility that the retroviral vector acti vated the gene, leading to the boy's illness.

The suspension of German trials earlier this year followed a report that a retroviral gene therapy had caused leukaemia in mice (Z. Lietal.Science 296, 497; 2002). Christopher Baum, the study's principal investigator, who is currently at the Cincinnat Children's Hospital Medical Center, says that the German authorities will let the trials continue after doctors revise their informed-consent documents to tell patients about the risk of cancer.

Baum and his co-authors suspect that a particular marker gene used in their study played a part in causing leukaemia. Therefore, Baum and Fischer say, the Science finding by itself did not justify halting all trials that use retroviral vectors.

"Until now, this was a perfect therapy for SCID. Now there are risks," says Don Kohn, a paediatrician at Children's Hospital of Los Angeles who was leading a genetherapy trial for SCID. Kohn has treated four children, all of whom are still healthy, but the FDA has now suspended his trial. Additional reporting by Quirin Schiermeier.

\section{Discovery of giant asteroid gives Pluto a rocky outlook}

\section{Tony Reichhardt, Washington}

Two astronomers at the California Institute of Technology have found a 1,200-kilometre-wide rock in the Kuiper Belt that circles in the region of Neptune's orbit.

The rock - named Quaoar after the creation force of the tribe that once inhabited the Los Angeles area, where the institute is based - is the largest of the 600-plus Kuiperbelt objects (KBOs) so far identified. And with a diameter half as big as Pluto's and roughly the same size as that of its moon Charon, Quaoar bolsters the argument that Pluto can also be considered a KBO.

Chad Trujillo and Mike Brown found Quaoar on a digital image taken on 4 June with the Palomar Observatory's 1.2-metre Oschin Telescope, which they set up to search

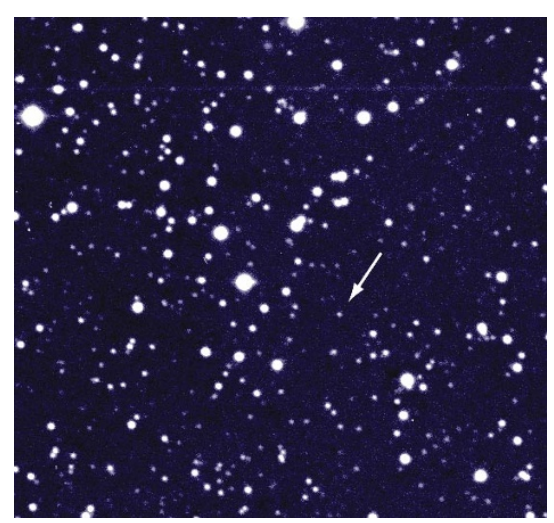

Big issue: the large size of Quaoar raises the question of whether Pluto is a Kuiper-belt object. for objects moving against the background star field. The pace of KBO discovery has accelerated in recent years, thanks to this and other Kuiper-belt searches that can spot even fainter objects.

Since the discovery, Trujillo and Brown have used the Hubble Space Telescope, the Keck telescope in Hawaii, and the IRAM millimetre-wave telescope in Spain to collect further details about Quaoar. With the benefit of hindsight, they have identified Quaoar in astronomical images taken as far back as 1982. It appears to be spherical, or nearly so - unlike another large KBO, the 900-kilometre Varuna, which is elongated.

Quaoar is also relatively bright, reflecting $10 \%$ of the light that hits it. This adds to evidence that the $4 \%$ reflectivity assumed for KBOs may be wrong. And because the size of such objects is often inferred from their brightness, Trujillo says that many KBOs may be smaller than originally believed. Two other KBOs - Ixion and 2002 AW197 — were once thought to be as big as Quaoar, assuming 4\% reflectivity. But Trujillo says that Quaoar's size has been confirmed by measurements from Hubble, whereas the others' haven't.

Alan Stern, a planetary scientist at Southwest Research Institute in Boulder, Colorado, and leader of the New Horizons spacecraft mission to reach Pluto by 2015, called Quaoar "a wonderful discovery". But its size record may turn out to be short-lived. Stern won't be surprised if someone eventually finds an Earth-sized object in the Kuiper belt. In fact, he adds, "I'd be surprised if we don't".

\section{Call for clinical-trial reform leaves critics unmoved}

\section{Kendall Powell, Washington}

Medical watchdog groups in the United States say they are becoming frustrated that reforms of the clinical-research system have failed to materialize, despite repeated calls for tougher regulation.

On 3 October, the Institute of Medicine released a report calling for modest reforms of the system. The report, "Responsible Research: A Systems Approach to Protecting Research Participants", was written by a panel chaired by Daniel Federman, senior dean for alumni relations and clinical teaching at Harvard University.

The report calls for all research on human subjects to be federally regulated, and recommends the creation of an independent office to oversee such research, and a national registry to track participants and adverse events in all clinical trials. But critics says that this is the fourth such report in five years, and that little has changed in the way that clinical research is regulated.

As the report was released, Senator Edward Kennedy (Democrat, Massachusetts) was introducing legislation to implement some of its main recommendations. But similar legislation has previously languished in the face of opposition from drug firms, medical schools and biomedical researchers.

"We've been talking about this for too long," says John Mather, chief officer for research oversight at the Department of Veterans Affairs. "Who is going to take that report off the table and do something with it?"

Critics of the existing system have nevertheless welcomed the report. It will get "everyone on the same page to deal with problems in clinical research", says Paul Gelsinger, whose son Jesse died while participating in a 1999 gene-therapy clinical trial at the University of Pennsylvania.

But some argue that the report fails to recommend the tough new rules that they would like to see applied to clinical trials. "When things aren't mandatory, nobody pays attention, and that's not going to change the rate of violations, death or harm," says Vera Sharav, president of the Alliance for Human Research Protection.

The report was commissioned by the Department of Health and Human Services after Jesse Gelsinger's death, in response to concerns that institutional review boards do not provide adequate protection for research subjects. 